\title{
Self-reported menstrual migraine in the general population
}

\author{
Kjersti Grøtta Vetvik • E. Anne MacGregor • \\ Christofer Lundqvist • Michael Bjørn Russell
}

Received: 14 December 2009/Accepted: 1 February 2010/Published online: 26 February 2010

(C) Springer-Verlag 2010

\begin{abstract}
A number of women with migraine experience increased incidence of attacks during the perimenstrual period. The Appendix of the International Classification of Headache Disorders (ICHD II) describes two types of migraine without aura related to menstruation: pure menstrual migraine (PMM) and menstrually related migraine (MRM). The phrase "menstrual migraine" is often used to cover both PMM and MRM. Although menstrual migraine is well recognized, further scientific evidence is needed before these definitions can be formally included in the ICHD III. The aim of the present study was to investigate the prevalence of PMM and MRM in the general population in Norway. The survey included 15,000 women, 30-44 years old, residing in the eastern part of Norway. They received a postal questionnaire containing six questions about migraine, headache frequency and the relation of migraine and menstruation. The study included 11,123 women. The questionnaire response rate was $77 \%$. The prevalence of self-reported migraine was $34.8 \%$. Of the migraineurs, $21 \%$
\end{abstract}

K. G. Vetvik ( $\square)$. C. Lundqvist · M. B. Russell Head and Neck Research Group, Research Centre, Akershus University Hospital, 1478 Lørenskog, Oslo, Norway

e-mail: kjersti.vetvik@medisin.uio.no

K. G. Vetvik · M. B. Russell

Faculty Division, Akershus University Hospital,

University of Oslo, 1474 Nordbyhagen, Oslo, Norway

E. A. MacGregor

The City of London Migraine Clinic,

22 Charterhouse Square, London EC1M 6DX, UK

C. Lundqvist

Department of Neurology, Oslo University Hospital Ullevål, 0407 Oslo, Norway reported migraine related to menstruation in at least two of three menstrual cycles, of which $7.7 \%$ were considered to have PMM and 13.2\% MRM. This corresponds to the prevalence of PMM and MRM in the general population of 2.7 and $4.6 \%$, respectively. Thus, self-reported menstrual migraine among women aged 30-44 years appears to be common in the general population in Norway.

Keywords Menstrual migraine - Prevalence · Epidemiology $\cdot$ General population

\section{Introduction}

The prevalence of migraine prior to puberty is $4 \%$ in boys and girls [1]. After menarche and during women's reproductive years, the prevalence increases significantly more in women than in men, and so the male: female ratio shifts from 1:1 to 1:2-3 [2-4]. Migraine onset is associated with menarche [5] and often declines after menopause [6]. More than $50 \%$ of women with migraine, both in the general population and presenting to headache clinics, report an association between menstruation and migraine [7,8]; 7-14\% experience attacks only during menstruation [9-13].

The International Classification of Headache Disorders II (ICDH II) defines the criteria for pure menstrual migraine (PMM) and menstrually related migraine (MRM) in the Appendix [14]. PMM is defined as migraine without aura that occurs exclusively on day $1 \pm 2$ of menstruation in at least two out of three menstrual cycles. MRM has additionally attacks of migraine without aura beyond the perimenstrual period. The term "menstrual migraine" is often used to describe both PMM and MRM together. Although the two types of migraine related to menstruation are likely to be distinct subtypes of migraine without aura, 
further scientific evidence is needed before these terms can formally be accepted in the future ICHD III.

Previous studies indicate that attacks of PMM and MRM are more severe, longer lasting, less responsive to acute treatment and give a higher work-related disability than non-menstrual attacks $[15,16]$. Despite this fact, PMM and MRM often remain under-recognized and under-treated by general practitioners and neurologists. Few studies provide information on the prevalence of menstrual migraine in the general population, and the prevalence varies significantly in different studies.

The aim of our study was to estimate the prevalence of self-reported migraine, PMM and MRM, among women aged 30-44 years from the general Norwegian population.

\section{Methods}

\section{Sampling}

This was a retrospective cross-sectional study based on an age-stratified sample of 15,000 women, 30-44 years old, residing in the eastern Akershus County in Norway. The sample was drawn from the National Personal Registry. Since this was a part of "The Akershus study of chronic headache", this age limit was defined in advance $[17,18]$.

Akershus County has both rural and urban areas and is situated in close proximity to Oslo. Data from Statistics Norway shows that the sampling area was representative of the total Norwegian population regarding age and marital status. Employment, trade, hotel/restaurant and transport were overrepresented, whereas industry, oil and gas and financial services were under-represented in the sampling area compared with the total Norwegian population (Statistics Norway, 2007; http://statbank.ssb.no/statistikkbanken/). The total population of the sampling area was 338,670, which is $7.4 \%$ of the Norwegian population. Our sample represents $36.6 \%$ of women in this age group in the eastern municipalities of Akershus County and $2.9 \%$ of women in Norway.

\section{Questionnaire}

The women received a short screening questionnaire with a standard letter containing information about the project. Apart from insuring confidentiality and emphasizing the importance of participation, it was stated that the object was to study headache. The questionnaire included questions about headache frequency within the last month and year, migraine within the last year and earlier, and whether the migraine was associated with menstruation and, if so, how often it occurred in relation to menstruation. If the questionnaire evoked no response, a second and subsequently a third mail were issued.

Classification

The ICHD II appendix criteria for PMM (A1.1.1) and MRM (A 1.1.2) were used [14]. Women with self-reported migraine and self-reported migraine in at least two of three menstrual periods were classified as "menstrual migraine", i.e., PMM or MRM. PMM was defined as migraine without aura that occurred exclusively on day $1 \pm 2$ of menstruation in at least two out of three menstrual cycles. MRM had additionally attacks of migraine without aura outside the perimenstrual period. The median length of the menstrual cycle was 28 days (usual range, 25-36 days), which gives 10-14 menstrual periods a year [19]. The mean duration of a menstrual migraine attack has been estimated at $33.7 \mathrm{~h} \mathrm{[16].}$ Thus, we classified women who reported in at least two out of three cycles $\leq 6$ days of headache in the last month and $\leq 30$ days of headache in the last year as having PMM, while the remaining women were classified as having MRM.

Since the relation of migraine and menstruation cannot be established with certainty in women with chronic headache, i.e., $\geq 15$ headache days within the last month or $\geq 180$ headache days within the last year, we excluded these women from the analysis. The analyses of migraine prevalence were based on all who had a positive response to the question about ever having had migraine.

Data processing and statistical methods

All questionnaires were scanned using TeleForm v9. Statistical analyses were performed using SPSS Base System for Windows 15.0 (SPSS Inc., Chicago, IL, USA). Prevalence rates were calculated using the Vassar College statistics Web page and are presented with $95 \%$ confidence intervals (2009; http://faculty.vassar.edu/lowry/VassarStats.html).

\section{Ethical issues}

The Regional Committees for Medical Research Ethics and the Norwegian Social Science Data Services approved the project. Participation was based on informed consent.

\section{Results}

Figure 1 is a flowchart of the population-based sample. The sample size was reduced to 14,436 because of error in the address list ( $n=535)$, emigration $(n=19)$, multi-handicap $(n=9)$ and death $(n=1)$. The overall response rate of the questionnaire was $77 \%$ (11 123/14 436). The questionnaire response rate among women within the three age groups, 30- 


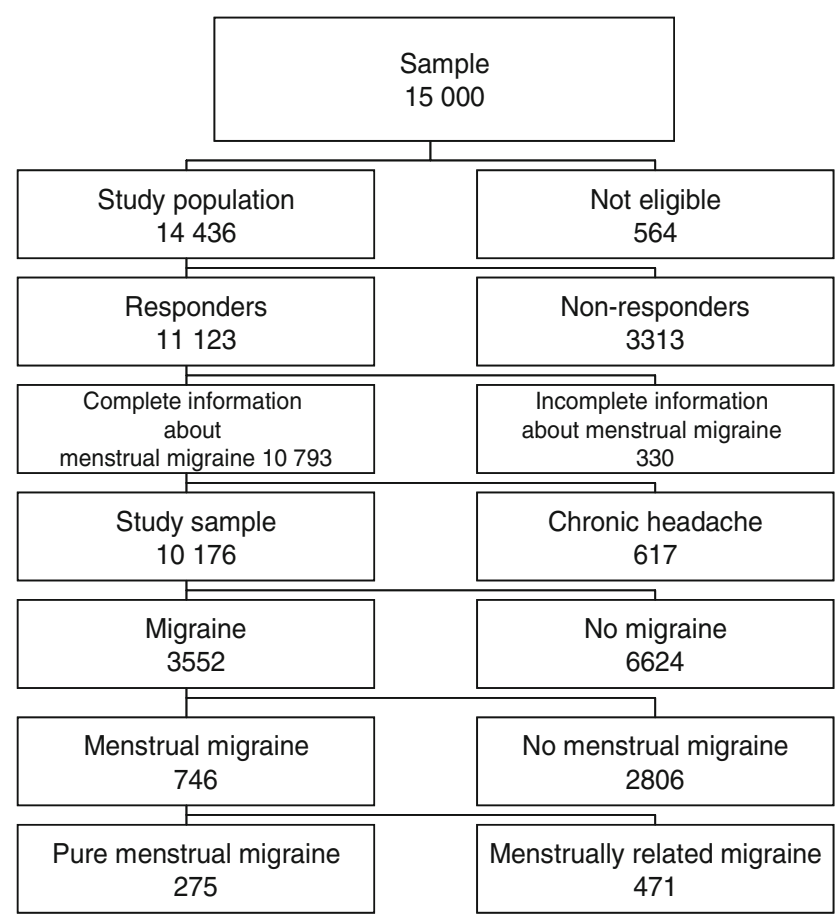

Fig. 1 Flowchart

$34,35-39$ and 40-44 years, increased significantly with age (73, 77 and $81 \% ; P<0.001)$. Information regarding headache in the last month and year, migraine previously and within the last year, migraine related to menstruation and frequency of migraine related to menstruation were missing in $0.2 \%$ (17/11 123), $0.4 \%$ (39/11 123), 1.0\% (107/11 123), $1.5 \%$ (162/11 123), $2.0 \%$ (223/11 123) and 2.2\% (43/1 927) of the questionnaires. Excluding those with chronic headache (617) and those with missing information about migraine previously and migraine in relation to menstruation reduced the study sample to 10,176 women.
Prevalence of pure menstrual migraine and menstrually related migraine

The prevalence of self-reported migraine was $34.8 \%$ (3 $552 / 10$ 176). Among the migraineurs, $21 \%$ (746/3 552) had self-reported migraine in relation to menstruation, of which $7.7 \%$ (275/3 552) had PMM and $13.2 \%$ (471/3 552) had MRM. The prevalence of PMM and MRM in the general population was $2.7 \%$ (275/10 176) and 4.6\% (471/10 176), respectively. The prevalence of self-reported migraine, PMM and MRM, increased with age (Table 1).

\section{Discussion}

Strengths and limitations

Our large population-based sample of women and the high questionnaire response rate provide population-based data on menstrual migraine from the general Norwegian population. Questionnaires are generally not valid for diagnosing migraine and headache [20]. However, simple questions such as: "Have you ever had migraine?", "How many headache days did you experience within the last month?" and "How many headache days did you experience within the last year?" are valid, as comparison with physician-conducted interviews showed high $\kappa$ values of $0.77-0.81$ [20-22]. As this was an epidemiological survey on headache, headache may be over-represented among responders of the questionnaire. We were not able to investigate whether responder and non-responders had a similar migraine and headache pattern, since for ethical reasons we were not allowed to contact non-responders. However, a Danish epidemiological survey based on a short migraine screening questionnaire found no significant difference in the frequency of migraine among responders

Table 1 Results: lifetime prevalence of migraine and menstrual migraine

\begin{tabular}{|c|c|c|c|c|}
\hline & \multicolumn{4}{|l|}{ Age (years) } \\
\hline & $\begin{array}{l}30-34 \\
n=3,245(\%)\end{array}$ & $\begin{array}{l}35-39 \\
n=3,410(\%)\end{array}$ & $\begin{array}{l}40-44 \\
n=3,521(\%)\end{array}$ & $\begin{array}{l}\text { All } \\
n=10,176(\%)\end{array}$ \\
\hline \multicolumn{5}{|l|}{ Prevalence among all women } \\
\hline All migraine & $33.3(31.4-34.6)$ & $35.1(33.6-36.8)$ & $36.1(34.5-37.7)$ & $34.9(34.0-35.8)$ \\
\hline Pure menstrual migraine & $2.0(1.6-2.6)$ & $2.8(2.3-3.3)$ & $3.2(2.8-3.8)$ & $2.7(2.4-3.0)$ \\
\hline Menstrually related migraine & $4.5(3.8-5.2)$ & $4.7(4.0-5.4)$ & $4.7(4.0-5.4)$ & $4.6(4.2-5.0)$ \\
\hline All menstrual migraine & $6.6(5.8-7.4)$ & $7.5(7.0-8.4)$ & $7.8(6.9-8.7)$ & $7.3(6.8-7.8)$ \\
\hline \multicolumn{5}{|l|}{ Prevalence among migraineurs } \\
\hline Pure menstrual migraine & $6.3(4.9-7.8)$ & $8.0(6.5-9.5)$ & $8.7(7.2-10.2)$ & $7.7(6.9-8.7)$ \\
\hline Menstrually related migraine & $13.5(11.5-15.5)$ & $13.3(11.3-15.3)$ & $13.0(11.0-15.0)$ & $13.2(12.1-14.3)$ \\
\hline All menstrual migraine & $19.8(17.4-22.2)$ & $21.4(19.1-23.7)$ & $21.7(19.4-24.0)$ & $20.9(19.7-22.4)$ \\
\hline
\end{tabular}

The figure in parenthesis indicate $95 \%$ confidence interval 
and non-responders [21]. We included women aged 3044 years old, since this was a part of another study. Thus, we did not have prevalence data on those who were younger or older.

Our questionnaire did not enable the full set of criteria for a precise ICHD II appendix diagnosis of PMM and MRM. For that reason, we classified PMM and MRM based on information of self-reported headache frequency. Some women with PMM and co-occurrence of frequent non-migraine headache might have been classified as MRM in our sample. On the other hand, women with short lasting attacks of MRM might have been classified as PMM. The prevalence of PMM and MRM in our study can therefore give a hint of the "true" prevalence. The golden standard, a clinical interview and a headache diary, kept for at least 3 months, would have given us the opportunity for more precise headache diagnoses and prevalence estimates, although such studies may suffer from non-compliance [23, 24].

The questions "Do you have migraine in relation to menstruation?" and "How often do you have migraine in relation to menstruation?" have not been validated. But due to the fact that self-reported migraine and headache frequency are valid questions, we assume that women with migraine do know whether they have migraine in relation to their menstruation as well as whether this occurs in all or only some of the menstrual cycles.

The questionnaire does not distinguish between migraine with and without aura. According to the ICHDclassification, PMM and MRM are defined as migraine without aura. We might have included some women with migraine with aura, which may lead to a higher prevalence of PMM and MRM. However, migraine without aura is 2.2 times more prevalent in women than migraine with aura, which seldom occurs in relation to menstruation $[2,25]$ We do not have information about the use of oral contraception, other hormonal treatment and pregnancy, which may influence the headache pattern of these women. Furthermore, we have not investigated exactly on which days of the menstrual period the migraine attacks occurred and can therefore not be sure that the attacks of migraine related to menstruation were exclusively on day $1 \pm 2$ according to the ICHD-definition. Because this was a retrospective study, recall bias may play a role. Many women have negative attitudes toward menstruation and this influences their reports of menstrual symptoms, including migraine. The more a woman believes in the phenomenon of menstrual distress, the more she exaggerates the negativity of her symptoms. She is more likely to recall inaccurately that menstrual-associated symptoms are more severe than prospective diaries actually show [26]. This might lead to a higher prevalence of menstrual migraine than in reality.

\section{Results}

The lifetime prevalence of migraine in our female population was $34.8 \%$. This is similar to that found in other epidemiological surveys of this age group conducted in Sweden, Holland, Norway, USA and Germany [22, 27-30]. In another cross-sectional population-based survey performed in the same county, as well as neighboring counties in Norway, the lifetime prevalence of migraine in women was $34.1 \%$ [22]. The prevalence of all menstrual migraine among migraineurs was $21 \%$ in our study. This is similar to figures from Danish and Swedish population-based studies and an American clinic population of gynecologic/obstetrician patients $[2,30,31]$. Our prevalence of pure PMM was similar to British findings, applying almost the same definition [10]. Our $13.2 \%$ prevalence of MRM corresponds to the $10.1 \%$ prevalence in an American study, while it is much lower than in most other studies, where the prevalence varies between 35 and 71\% [9-13, 30]. Our results were based on a group of women with menstrual migraine from which we subtracted those with assumed PMM. Our data are based on mean attack duration of $33.7 \mathrm{~h}$. However, if some of the women with PMM had longer attacks, they might wrongly be assigned to the group of those with MRM. Thus, our low prevalence of MRM is not likely to be explained by our methods of calculation. The large disparity in the prevalence may be due to the former lack of a consistent definition of menstrual migraine, different study populations and study design.

All of the studies listed below, with the exception of two, were performed before the present definitions of PMM and MRM were introduced to ICHD II (Table 2). In particular, the definition of MRM has been vague. There were several women in our study (i.e., 717) who claimed to have migraine related to menstruation, but had it less than in two out of three menstrual cycles (i.e., "one out of two cycles" or "seldom"). According to the definition, we did not include these women. If they had been included, we would have a prevalence of $41.2 \%$ (1 463/3 552), which is more similar to studies conducted before the current definition.

Our prevalence in the general population of PMM and MRM was 2.7 and $4.6 \%$, respectively. These numbers are higher than the results from a Dutch population-based survey [15]. The studies are not directly comparable due to different definitions of menstrual migraine and different study samples (women with regular cycles vs. all women).

As much as 5.7\% (617/10793) of the women were excluded from our sample because of chronic headache. Approximately $50 \%$ of women with chronic headache have co-occurrence of migraine and only about $20 \%$ of them are expected to have menstrual migraine [18]. The exclusion of these women does not therefore make a substantial impact on our prevalence of menstrual migraine. 


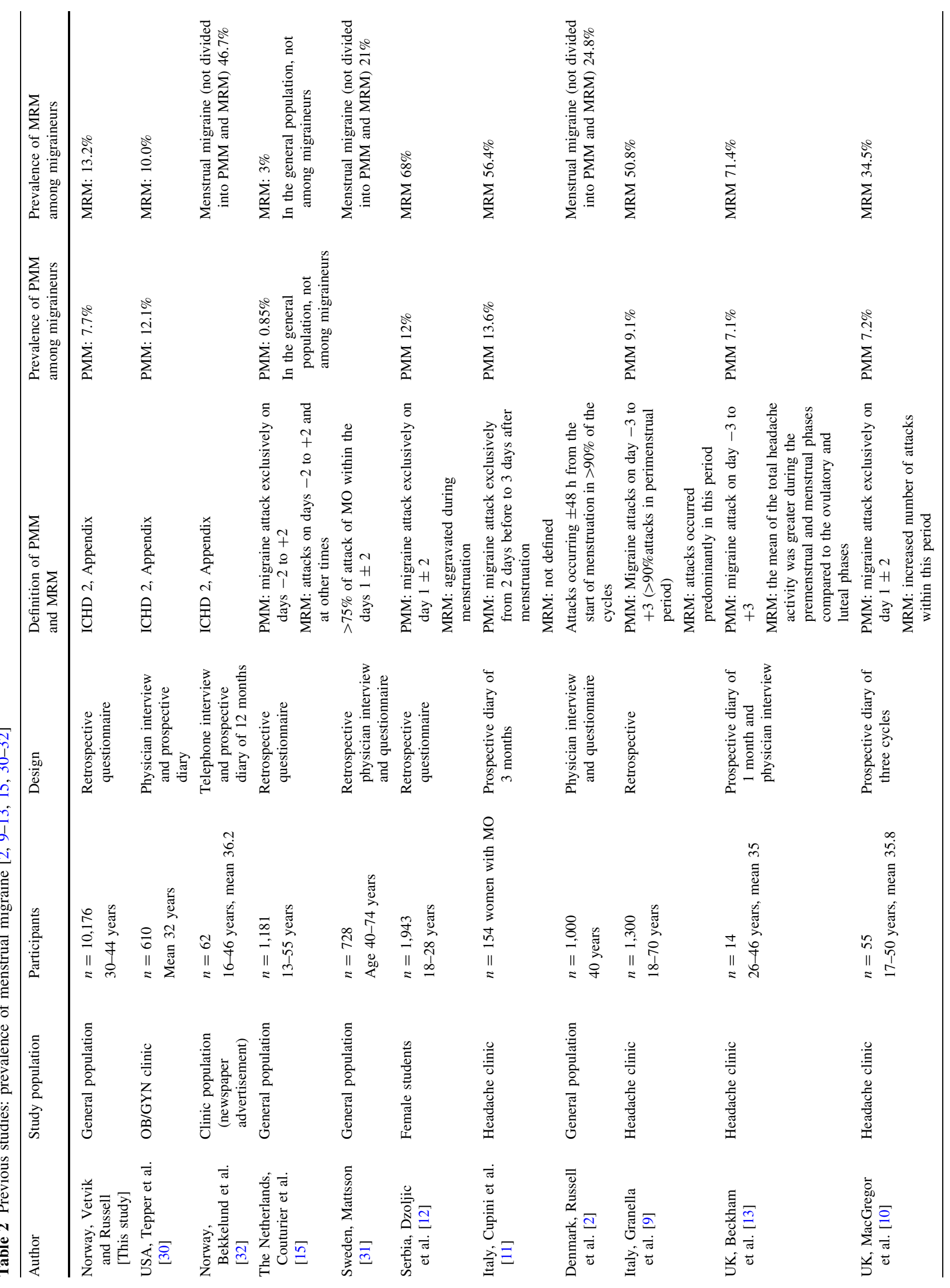




\section{Conclusion}

Menstrual migraine appeared to be common among women aged 30-44 years old in the general population in Norway. Improved knowledge from large prospective populationbased studies, with diary-confirmed diagnosis as well as clinical trials for improved management is indicated.

Acknowledgments This study was supported by grants from the East Norway Regional Health Authority and Faculty Division Akershus University Hospital. KGV was supported by the University of Oslo.

Conflict of interest The authors declare no relevant conflicts of interest.

\section{References}

1. Bille B (1962) Migraine in school children. A study of the incidence and short-term prognosis, and a clinical, psychological and electroencephalographic comparison between children with migraine and matched controls. Acta Paediatr Suppl 136:1-151

2. Russell MB, Rasmussen BK, Fenger K, Olesen J (1996) Migraine without aura and migraine with aura are distinct clinical entities: a study of four hundred and eighty-four male and female migraineurs from the general population. Cephalalgia 16:239-245

3. Rasmussen BK, Jensen R, Schroll M, Olesen J (1991) Epidemiology of headache in a general population-a prevalence study. J Clin Epidemiol 44:1147-1157

4. Takele GM, Tekle HR, Martelletti P (2008) Prevalence and burden of primary headache in Akaki textile mill workers, Ethiopia. J Headache Pain 9:119-128

5. Epstein MT, Hockaday JM, Hockaday TD (1975) Migraine and reproductive hormones throughout the menstrual cycle. Lancet 1:543-548

6. Stewart WF, Simon D, Shechter A, Lipton RB (1995) Population variation in migraine prevalence: a meta-analysis. J Clin Epidemiol 48:269-280

7. Granella F, Sances G, Pucci E, Nappi RE, Ghiotto N, Nappi G (2000) Migraine with aura and reproductive life events: a case control study. Cephalalgia 20:701-707

8. MacGregor EA, Igarashi H, Wilkinson M (1997) Headaches and hormones: subjective versus objective assessment. Headache Q 8:126-136

9. Granella F, Sances G, Zanferrari C, Costa A, Martignoni E, Manzoni GC (1993) Migraine without aura and reproductive life events: a clinical epidemiological study in 1300 women. Headache 33:385-389

10. MacGregor EA, Chia H, Vohrah RC, Wilkinson M (1990) Migraine and menstruation: a pilot study. Cephalalgia 10:305310

11. Cupini LM, Matteis M, Troisi E, Calabresi P, Bernardi G, Silvestrini M (1995) Sex hormone-related events in migrainous females. A clinical comparative study between migraine with aura and migraine without aura. Cephalalgia 15:140-144

12. Dzoljic E, Sipetic S, Vlajinac H, Marinkovic J, Brzakovic B, Pokrajac $M$ et al (2002) Prevalence of menstrually related migraine and nonmigraine primary headache in female students of Belgrade University. Headache 42:185-193

13. Beckham JC, Krug LM, Penzien DB, Johnson CA, Mosley TH, Meeks GR et al (1992) The relationship of ovarian steroids, headache activity and menstrual distress: a pilot study with female migraineurs. Headache 32:292-297

14. Headache Classification Subcommittee of the International Headache Society (2004) The International Classification of Headache Disorders, 2nd edn. Cephalalgia 24 Suppl 1:9-160

15. Couturier EG, Bomhof MA, Neven AK, van Duijn NP (2003) Menstrual migraine in a representative Dutch population sample: prevalence, disability and treatment. Cephalalgia 23:302-308

16. Granella F, Sances G, Allais G, Nappi RE, Tirelli A, Benedetto C et al (2004) Characteristics of menstrual and nonmenstrual attacks in women with menstrually related migraine referred to headache centres. Cephalalgia 24:707-716

17. Aaseth K, Grande RB, Kvaerner KJ, Gulbrandsen P, Lundqvist C, Russell MB (2008) Prevalence of secondary chronic headaches in a population-based sample of 30-44-year-old persons. The Akershus study of chronic headache. Cephalalgia 28:705-713

18. Grande RB, Aaseth K, Gulbrandsen P, Lundqvist C, Russell MB (2008) Prevalence of primary chronic headache in a populationbased sample of 30- to 44-year-old persons. The Akershus study of chronic headache. Neuroepidemiology 30:76-83

19. Beers MHPRS (2006) The Merck manual of diagnosis and therapy, 18th edn. Merck Research Laboratories, Whitehouse Station

20. Rasmussen BK, Jensen R, Olesen J (1991) Questionnaire versus clinical interview in the diagnosis of headache. Headache 31:290-295

21. Russell MB, Rasmussen BK, Thorvaldsen P, Olesen J (1995) Prevalence and sex ratio of the subtypes of migraine. Int $\mathrm{J}$ Epidemiol 24:612-618

22. Russell MB, Kristiansen HA, Saltyte-Benth J, Kvaerner KJ (2008) A cross-sectional population-based survey of migraine and headache in 21, 177 Norwegians: the Akershus Sleep Apnea Project. J Headache Pain 9:339-347

23. Russell MB, Rasmussen BK, Brennum J, Iversen HK, Jensen RA, Olesen J (1992) Presentation of a new instrument: the diagnostic headache diary. Cephalalgia 12:369-374

24. Russell MB, Iversen HK, Olesen J (1994) Improved description of the migraine aura by a diagnostic aura diary. Cephalalgia 14:107-117

25. Stewart WF, Lipton RB, Chee E, Sawyer J, Silberstein SD (2000) Menstrual cycle and headache in a population sample of migraineurs. Neurology 55:1517-1523

26. McFarland C, Ross M, DeCourville N (1989) Women's theories of menstruation and biases in recall of menstrual symptoms. J Pers Soc Psychol 57:522-531

27. Mattsson P, Svardsudd K, Lundberg PO, Westerberg CE (2000) The prevalence of migraine in women aged 40-74 years: a population-based study. Cephalalgia 20:893-899

28. Launer LJ, Terwindt GM, Ferrari MD (1999) The prevalence and characteristics of migraine in a population-based cohort: the GEM study. Neurology 53:537-542

29. Gobel H, Petersen-Braun M, Soyka D (1994) The epidemiology of headache in Germany: a nationwide survey of a representative sample on the basis of the headache classification of the International Headache Society. Cephalalgia 14:97-106

30. Tepper SJ, Zatochill M, Szeto M, Sheftell F, Tepper DE, Bigal M (2008) Development of a simple menstrual migraine screening tool for obstetric and gynecology clinics: the menstrual migraine assessment tool. Headache 48:1419-1425

31. Mattsson P (2003) Hormonal factors in migraine: a populationbased study of women aged 40 to 74 years. Headache 43:27-35

32. Bekkelund SI, Alstadhaug KB, Salvesen R (2008) Lack of seasonal variation in menstrually related migraine. Cephalalgia 28:1277-1281 